\title{
ГАРМОНИЗАЦИЯ АРХИТЕКТУРЫ СИСТЕМЫ ВПО В УСЛОВИЯХ ИНТЕГРАЦИИ РОССИИ В БОЛОНСКИЙ ПРОЦЕСС
}

\author{
E.C. ЕРЁМЕНКО \\ Санкт-Петербургский государственный университет сервиса и экономики, \\ Институт региональной экономики и управления, \\ аспирант кафедры «Менеджмент таможенного и страхового сервиса». \\ Научный руководитель д.э.н., проф. Дроздов Г.Д.
}

\begin{abstract}
Аннотация:
Данная статья посвящена проблемам интеграции российской системы ВПО в Болонский процесс.

В ней проведен анализ ключевых проблем, с которыми столкнулась российская система высшего профессионального образования на пути реализации принципов Болонской декларации, показаны основные направления модернизации ВПО, освещены цели проводимых реформ, выявлены социальные эффекты, получаемые в процессе реализации принципов Болонского процесса.

В статье предлагается перечень образовательных задач, которые необходимо решить российским вузам в целях гармонизация архитектуры высшего профессионального образования в рамках Болонской декларации.

Ключевые слова: Система образования, интеграция в Болонский процесс, образовательные задачи, модернизация, качество образования, Болонская декларация, постадминистративная модель системы ВПО, либеральная модель системы ВПО.
\end{abstract}

\section{ВВЕДЕНИЕ}

Образование является важнейшей сферой социальной жизни. Именно образование формирует интеллектуальное, культурное, духовное состояние общества. Обеспечение доступности качественного профессионального образования для всех слоев населения является основой социальной мобильности и снижения социально-экономической дифференциации в обществе.

Необходимость модернизации системы образования СССР остро назрела уже в конце 80-х гг. XX в., так как она не отвечала запросам времени, утратила способность развиваться, использовать внутренние резервы.

Постадминистративные модели образовательных систем, сложившиеся на территории постсоветского пространства в последние 15 лет, являются результатом независимых поисков улучшения и преобразования унаследованных от плановой экономики систем образования стран постсоветского пространства и в деталях заметно отличаются друг от друга [2, стр. 31], что отражено в научных трудах В.С. Вахштайна, В.И.Горовой, Н.Ф.Петрова, Б.А.Сазонова и др.

Рассмотрим некоторые особенности постадминистративных образовательных систем, свойственных для постсоветского образовательного пространства, 
учитывая движение этих систем в направлении к либеральной модели образования, соответвтующей принципам Болонского процесса.

\section{РЕЗУЛЬТАТЫ И ИХ ОБСУЖДЕНИЕ}

Основные отличия постадминистративной модели от либеральной заключаются в следующем.

Государственные управляющие органы в образовании определяют перечни направлений подготовки и специальностей, а также контрольные цифры приёма студентов в образовательные учреждения. Федеральные государственные образовательные стандарты определяют необходимые требования для основных образовательных программ по всем входящим в перечни направлениям подготовки и специальностям. Кроме того, государство сдерживает инициативу вузов по открытию новых специальностей и направлений подготовки, т.к. это вёдет к увеличению расходов государственного бюджета.

Несмотря на то, что вузы имеют право обновлять основные образовательные программы, на практике они не прибегают к данной возможности, т.к. не имеют для этого достаточно стимулов. В итоге обновление реализуемых основных образовательных программ происходит одновременно с изменением федеральных государственных образовательных стандартов.

Проблемным аспектом в постадминистративных моделях также является система классификации образовательных программ. Всего в профессиональном образовании существует три классификатора: Общероссийский классификатор начального профессионального образования (ОКНПО), Общероссийский классификатор специальностей по образованию (ОКСО), и Общероссийский классификатор специальностей высшей научной классификации (ОКСНВК). Такая градация специальностей по уровням профессионального образования была унаследована от советской системы образования.

В условиях административно-командной экономики три независимые учреждения управляли профессиональным образованием. Каждое из них создавало классификатор для соответствующего уровня образования. Принципы классификации, существовавшие в СССР, были сохранены и применены в 90-е годы при переработке классификаторов в общероссийские.. При этом в основе горизонтальной классификации профессиональных образовательных программ были сохранены традиционные системно-различные принципы [6. С. 63].

Отличительной чертой классификации основных образовательных программ в постадминистративной модели профессионального образования является то, что система классификации сопряжена с перечнем образовательных программ. Поэтому, для того чтобы в образовательном учреждении ввести новую образовательную программу, необходимо внести изменения в соответствующий общегосударственный классификатор.

Из вышесказанного следует, что система ведения классификаторов в области профессионального образования является неудобной и неэффективной. Она затрудняет статистический учёт в образовании и оптимизацию распределения кадров по уровням профессионального образования. 
Следующим проблемным аспектом постадминистративной модели ВПО является постоянное увеличение студенческих контингентов, что обусловлено следующими причинами:

- отсутствием системы государственного регулирования подготовки специалистов ВПО, позволяющей влиять на распределение выпускников общеобразовательных школ в соответствии с требованиями и конъюнктурой рынка труда;

- спонтанно образовавшейся системой платных услуг в сфере ВПО, зачастую негативно сказывающейся на качестве образования;

- увеличением доступа к бюджетным местам государственных вузов, связанного с последствиями демографического кризиса.

Одной из особенностей постадминистративных систем образования является система подготовки кадров, характерная скорее для административнокомандной экономической системы, но являющаяся неэффективной в современных рыночных условиях.

Недостаточное финансирование высших образовательных учреждений в 90-е годы послужило причиной устаревания их материально-технической базы, снижению интенсивности и результативности научной деятельности, старению профессорско-преподавательского состава. Несмотря на то, что в последние несколько лет положение дел улучшается, в большинстве стран постсоветского пространства сохраняется недовольство общества качеством профессионального образования и результатами действий, направленных на решение данной проблемы

Большая часть этих проблем обусловлена несовершенной организацией процесса образования, недостаточным финансированием и неэффективной системой бюджетирования в сфере образования. Причины этих проблем общие большая часть управленческих механизмов, эффективно работавшая в условиях плановой экономики перестала работать в условиях перехода к рыночной экономической системе.

Выделим основные проблемы, свойственные постадминистративным образовательным системам:

1. Несовершенство механизма реализации конституционного права граждан на бесплатное получение высшего образования на конкурсной основе, следствием чего являются [1. С. 36]:

- наличие возможности обучения в государственных высших образовательных учреждениях слабоуспевающих студентов, т.к. при подушевом финансировании отчисление студентов для вузов становится крайне невыгодным мероприятием.

- потери средств федерального бюджета, связанные с отчислением студентов, на обучение которых уже затрачены государством значительные финансовые средства.

2. Фактическое отсутствие возможности формирование студентами индивидуальных планов и организации учебного процесса в соответствии с ними. Отсутствие возможности у студентов, большинство из которых вынуждены 
совмещать обучение с работой, гибко планировать свое учебное время приводит к снижению успеваемости и повышению процента отчислений.

3. Использование несовершенных систем оценки качества образования и контроля:

- осуществление образовательного процесса и оценки качества знаний студентов одним и тем же преподавателем, что зачастую не даёт реальной картины успеваемости студентов и снижает объективность оценки.

- практически полная зависимость студента от назначенного ему преподавателя

- проблема многочисленных пересдач, порой вынуждающая преподавателей ставить незаслуженные оценки, чтобы исключить повторные встречи с неуспевающими студентами

Таким образом, существование системы ВПО в рамках постадминистративной модели ведёт к сдерживанию развития образования или вовсе к его деградации. Все перечисленные проблемы постадминистративной модели ВПО тесно взаимосвязаны. Для их решения необходим комплекс мер, направленный на модернизацию всей образовательной системы, способствующий интернациональной гармонизации архитектуры высшего профессионального образования. Интеграция России в Болонский процесс дает новый импульс модернизации образования с расширением его доступности, повышением качества и конкурентоспособности, способствует переходу российской системы ВПО с постадминистративной модели на либеральную модель, отражающую принципы Болонского процесса.

Необходимо отметить, что в настоящее время продолжается работа по разработке новых государственных образовательных стандартов высшего профессионального образования, в основе которых лежит компетентностный подход, совершенствуется система качества образования, в связи с чем внедрены новые показатели государственной аккредитации, повышающие требования к условиям реализации программ высшего профессионального образования и переходу вузов из одного вида в другой, позволяющие привести качество российского высшего профессионального образования в соответствие с общеевропейским пониманием современного качества высшего образования.

Реализация положений Болонской декларации сделает полученное российским студентом образование понятным и приемлемым для европейских работодателей, а также для иностранных менеджеров на территории России; увеличит возможности студентов учиться по программам мобильности за границей; студенты смогут скорректировать выбор профессии и выбор вуза при переходе с уровня на уровень - из бакалавриата в магистратуру или из магистратуры в докторантуру. Гармонизация архитектуры высшего профессионального образования позволит студентам накапливать зачетные единицы и использовать их для получения второго высшего образовании, откроет новые возможности для глубокого изучения иностранных языков как в родном вузе, так и в странах, где на этих языках говорят. 
Следует отметить, что модернизация системы высшего образования происходит в условиях трансформации всех сфер общественной жизни России и осложняется значительным несовпадением российской модели с Болонским образцом в части продолжительности обучения, квалификационной структуры, направлений и содержания профессиональной подготовки, организации учебного процесса [2. С. 111].

В настоящее время в российской системе образования осуществляется внедрение систем менеджмента качества, экспериментальное введение в некоторых вузах системы зачетных единиц и европейских приложений к дипломам. Необходимо учесть, что переход к системе академических кредитов приведет к значительным изменениям в образовательном законодательстве, в структуре государственных образовательных стандартов, учебных планов, программ и учебных дисциплин. Ещё предстоит решить задачи по разработке нормативноправовых документов, регламентирующих содержательное наполнение, сопоставимость зачетных единиц, заработную плату профессорскопреподавательского состава.

К проблемам, которые необходимо решить в скором времени, относятся налаживание взаимодействия между высшими учебными заведениями и местным сообществом, активное участие вузов в региональном развитии, установление тесной связи институтов и университетов с работодателями, повышение финансовой устойчивости вузов, создание системы оценки качества образования.

Ревизии приоритетов образовательной политики и осуществлению качественных изменений в области высшего образования способствуют актуальные цели интернационализации высшего образования и интеграции его в европейское и международное образовательное пространство в контексте реализации Болонского процесса [2. С. 138].

Серьезными проблемами, с которыми столкнулась система ВПО в связи с интеграцией России в Болонский процесс, стали:

- инерционность восприятия рынком труда степени бакалавра. В связи с ликвидацией большинства привычных специальностей при переходе на ФГОС, работодатели отдают предпочтение магистрам [2. С. 1];

- отсутствие готовности российской высшей школы полноценно реализовывать программы мобильности в связи с недостаточным финансированием многих вузов и слабым знанием участниками программ иностранных языков;

- неготовность многих вузов к формированию новых компетенций выпускников, направленных на мобильность в рынке труда;

- отсутствие механизма сопоставимости академических программ.

В то же время ряд проблем по реализации положений Болонской декларации связан с тем, что образовательные стратегии Болонского процесса в России до сих пор четко не определены. Не разработана национальная стратегия в связи с присоединением к Болонскому процессу, не определена национальная идея интеграции России в единое европейское образовательное пространство, не созданы правовые условия для развития академической мобильности [2. С. 142] 
Кроме того, отдельной проблемой является уникальность российского рынка труда, потребности которого определяют социальный заказ к системе ВПО.

Особенность российского рынка труда проявляется в его региональном характере и существующей неопределенности перспектив развития отдельных отраслей и территорий. В этих условиях значительно снижаются возможности территориальной мобильности специалистов, в то время как повышается потребность в их профессиональной мобильности, обеспечиваемой дополнительными образовательными формами. С другой стороны, в условиях экономической нестабильности российского общества расширение академической мобильности таит в себе реальную угрозу превращения России в поставщика ресурсов для западноевропейских стран [6. С. 70].

Проводя анализ обязательств России по реализации принципов Болонской декларации, можно сказать о значительной неравномерности степени решения стоящих задач, использовании при этом различных методов и подходов, об отсутствии необходимой системности в общем построении и ходе работ по интеграции российской системы ВПО в Болонский процесс.

С одной стороны, подобная дифференциация действия вузов и их результатов говорит о том, что учебные заведения осуществляют все эти действия на основе имеющихся у них наработок и реальных ситуаций в системе сложившихся внутренних и внешних связей. Чрезмерное централизованное администрирование и формальное единообразие действия вузов были бы чреваты тем же формальным подходом и действиями учебных заведений перед реализациями стоящих задач. Но с другой стороны, слабость единого управления данными процессами ослабляет их динамику и приводит к отмеченному выше состоянию дел в рассматриваемой области.

Следует отметить, что преимуществами российской системы образования считаются высокое качество, фундаментальность и системность обучения. Потерю этих характеристик российские противники Болонского процесса связывают с сокращением нормативных сроков обучения и переходом к системе зачетных единиц. Кроме того, высказываются опасения, что внедрение болонской модели приведет к утрате специализаций, развалу кафедр и научных школ, сокращению занятости преподавателей.

Несмотря на движение к либеральной модели системы ВПО в рамках Болонского процесса сегодня образовательные учреждения сталкиваются с такими проблемами, как несоответствие существующих образовательных стандартов потребностям рынка труда, требованиям современного общества, отсутствием связи профессионального образования с научно-исследовательской и практической деятельностью, и рядом других проблем. В этой связи образовательная система требует изменений на национальном уровне. Таким образом, система обеспечения качества образования на общероссийском уровне должна предполагать: 
- пересмотр Государственных образовательных стандартов и их учебнометодического сопровождения для приведения содержания и технологий образования в соответствие:

a) требованиям современного общества (переход от передачи "готовых знаний" к формированию компетенций);

б) требованиям социально-экономического развития (преодоление рассогласования с потребностями рынка труда по отраслям и в территориальном разрезе);

в) современному уровню развития соответствующей отрасли и науки.

- формирование эффективных механизмов привлечения институтов гражданского общества (профессиональные и научные сообщества, объединения работодателей и пр.) к вопросам оценки качества образования от разработки стандартов до контроля за результатами образовательного процесса;

- обеспечение прямой связи профессионального образования с научноисследовательской и практической деятельностью через развитие эффективных организационных форм (инновационные университеты, базовые кафедры вузов в НИИ, научно-образовательные центры и др.), создание механизмов коммерциализации исследований и разработок (научные парки, центры передачи технологий и пр.);

- совершенствование процедур лицензирования, государственной аккредитации на базе независимой экспертизы, в том числе с привлечением международных организаций и экспертов;

- усиление контроля качества образования в филиалах и негосударственных образовательных учреждениях;

- совершенствование государственной аттестации научно-педагогических кадров;

- разработку стандарта учебно-материальной базы, регламентирующего необходимые и достаточные материально-технические нормы;

- создание внутренних механизмов контроля качества в образовательных учреждениях.

Особую роль в переходе российского профессионального образования на новый уровень играет необходимость разработки единой системы независимой оценки качества образования. В настоящее время оценка качества образования с точки зрения субъекта оценки (органов управления образованием, работодателей, образовательных учреждений, студентов) имеет скорее формальный, фрагментарный подход. Так оценка качества образования со стороны государства опирается на степень соответствия государственным стандартам, а со стороны работодателя на производительность труда молодых специалистов. В этом аспекте можно говорить об отсутствии научно доказанной закономерности между уровнем учебных оценок учащихся, количеством публикаций преподавателей, их остепененностью и производительностью труда учащихся в результате обучения, а также востребованностью данных специалистов на рынке труда. Таким образом, сравнивая объем знаний, умений и навыков, полученных учащимися в рамках учебного процесса с одной стороны и функциональными 
требованиями с необходимыми профессиональными компетенциями важными для работодателя с другой стороны, можно выявить невысокий уровень корреляции между знаниями и навыками, которые получает обучающийся в учебном заведении по избранной специальности и профессиональными требованиями, компетенциями соответствующими функциональным обязанностям, которые востребованы в коммерческих и государственных организациях.

Образовательные учреждения, являясь экономически, юридически и административно зависимыми от государственных органов управления образованием, стоят перед необходимостью решать достаточно трудные задачи сочетания соответствия государственным образовательным стандартам и созданием учебного продукта, обеспечивающего качественную подготовку в будущем конкурентноспособного специалиста по выбранной специальности на рынке труда.

Учащиеся, в большинстве своем, не могут объективно оценить ни процесс, ни результат обучения, так как не владеют достаточной информацией о профессиональных требованиях, компетенциях выбранной специальности. В лучшем случае обучающиеся могут оценить качество коммуникации, организации процесса образования и объем передачи информации.

Фактически результаты деятельности образовательных учреждений оценивает работодатель. Но, к сожалению, на сегодняшний день работодатели в целом не участвуют, ни в формировании правовой образовательной базы, образовательных стандартов, ни в создании образовательного продукта, ни в подборе преподавателей учебными заведениями. В лучшем случае работодатели могут участвовать в реализации учебного процесса через соучастие в организации учебных, производственных и преддипломных практик, рецензировании содержания учебного продукта, оказании консультативной помощи образовательным учреждениям. В результате неформальная оценка качества образования работодателем заключается в уровне востребованности выпускников отдельных вузов и специальностей на рынке труда.

\section{ВЫВОДЫ}

Таким образом, можно говорить о том, что для повышения качества образования необходимо обеспечить разработку системы обратной связи между всеми субъектами образовательного процесса с целью формирования единой системы оценки качества образования с учетом оценки использования результата образования.

Таким образом, в целях решения проблем, связанных с интеграцией российской системы ВПО в Болонский процесс, вузам нашей страны предстоит решить следующие задачи:

- создать и развивать систему грантов для студентов и преподавателей, разработать её оценку и ввести в качестве компонента в национальный рейтинг вузов, ожидая, что такая оценка станет со временем частью европейского рейтинга;

- ввести обязательный международный компонент в учебные программы;

- внедрить систему европейских зачетных единиц; 
- ввести систему менеджмента качества, основанную на международных стандартах;

- изыскать возможности для увеличения академической мобильности преподавателей, студентов и руководства;

- стимулировать преподавателей и менеджеров на изучение иностранных языков;

- создать инфраструктуру для поддержки и адаптации, социальной и культурной поддержки приезжающих иностранных студентов, условий проживания, предоставления достоверной информации о возможности обучения в российских вузах.

Известно, что образование играет особую роль в утверждении национального самосознания и культурной самобытности каждого народа, его самоидентификации. Российское образование базируется на культурных и педагогических национальных традициях и приоритетах, имеет глубокие исторические корни и формируется с учетом российской ментальности. Высокая социальная значимость сферы образования не позволяет превращать её в площадку для необдуманных экспериментов [5, С. 86]. Поэтому развернувшиеся в европейской системе образования интеграционные процессы должны развиваться на принципах взаимообогащения национальных образовательных систем, обязательного сохранения их культурной самобытности, гарантией чего является добрая воля всех стран - участников Болонского процесса [2, стр. 113].

\section{ЛИТЕРАТУРА}

1. Бадарч, Д. Актуальные вопросы интернациональной гармонизации образовательных систем / Д. Бадарч, Б.А. Сазонов. - М.: Бюро ЮНЕСКО в Москве; ТЕИС, 2007. - 190с.

2. Гретченко, А.И. Болонский процесс: интеграция России в европейское и мировое образовательное пространство/ А.И. Гретченко, А.А. Гретченко - М.: КНОРУС, 2009.-432c.

3. Зуев, В.М. Болонский процесс и проблемы высшего экономического образования. / В.М. Зуев. - М.: НИИВО, 2005. - 212с.

4. Киселев, А.Ф. Образовательный потенциал России: состояние и развитие / А.Ф. Киселев, А.Я. Савельев, Б.А. Сазонов - М.: МГУП, 2004. $136 \mathrm{c}$.

5. Пастухов, А.Л. Тенденции управления знаниями в университетских комплексах/ А.Л. Пастухов // Экономика и управление - 2010- № 10 - С. 86-89.

6. Пастухов, А.Л. Теоретические аспекты управления знаниями в университетском комплексе / А.Л.Пастухов// Экономическое возрождение России - 2010 - № 3 - С. 62-71. 